\title{
13 \\ Reid on Favors, Injuries, and the Natural Virtue of Justice
}

\author{
Lewis Powell and Gideon Yaffe
}

\section{Introduction}

David Hume famously claims that justice is morally good-worthy of moral approval-only thanks to certain social conventions. To give people the objects they deserve-i.e., those that are due to them-as when we return to someone an object that fell from his pocket, is not a natural, but an artificial virtue. In hypothetical worlds lacking social conventions, either because none is needed or because the need they serve has not yet been met through the construction of a convention, there would be nothing morally good about being disposed to distribute goods in accord with the bounds of ownership. Thomas Reid is among the many of Hume's contemporaries scandalized by this idea. Surely, thinks Reid, Hume is denigrating the grand and important virtue of justice. However, unlike some who take Hume's alleged denigration of the virtue of justice to be reason enough to reject his view of it, Reid offers a counterargument intended to show not just that the virtue is natural, but that anyone who accepts, as Hume does, that the affections of gratitude and resentment are natural is committed, also, to the claim that even in a state of nature, lacking in human conventions, justice would be morally good and approved as such. So, Reid tries to show that Hume himself is tacitly committed to what he so fervently denies.

Reid states the central ideas behind his argument as follows:

A favour, an act of justice and an injury, are so related to one another that he who conceives one must conceive the other two ... As soon, therefore, as men come to have any proper notion of a favour and of an injury; as soon as they have any rational exercise of gratitude and of resentment; so soon they must have the conception of justice and of injustice; and if gratitude and resentment be natural to man, which Mr HUME allows, the notion of justice must be no less natural.

(EAP V v, 311)

The argument runs, roughly, as follows. ${ }^{1}$ Gratitude and resentment are natural feelings that we have, without help from social conventions, in response to good and bad

1 See EAP V v, esp. 306-11. 
things being given to us, and taken from us, by other people. But when someone who is rational possesses those feelings, they involve the recognition that the beneficial or harmful object bestowed by another was not deserved. The rational feel grateful only for being given what is not theirs, and resentful only when deprived of what is rightfully theirs. So, thinks Reid, implicit in our natural responses to receipt of that which we are not owed is the recognition that the object in question is not owed. It follows, thinks Reid, that the recognition of a certain act as just, as giving someone what he is due, and the attendant feelings involved in that recognition, are themselves natural. It is a further step from this conclusion to the proposition that justice is a virtue in the state of the nature; perhaps in the absence of conventions we recognize that some things are deserved by people and are even moved to bestow them on them without the disposition to do so being morally approved. But both Reid and, importantly, Hume accept, for different reasons, that this further step can be made. In short, the argument runs by deriving-from the facts about gratitude and resentment-premises that are sufficient to establish, by both Reid and Hume's lights, that justice is a natural virtue.

The argument has been discussed in passing by various commentators, but none has lingered on it. ${ }^{2}$ Our goal here is to bring out the details of the argument and explain how they are entrenched in other aspects of Reid's thought that are unacceptable to Hume for independent reasons. One of the points that emerges is that Hume's moral philosophy is rooted in his philosophy of mind and action more deeply than perhaps he himself realized. If it were not for the fact that he allows only a sparse set of principles through which mental phenomena can be explained, he would not be committed to the view that justice is an artificial virtue. Reject that sparse set of principles, as Reid does, and you have no reason to follow Hume in his claim that justice is an artificial virtue. Reid's argument succeeds, that is, given a philosophy of mind and action that Hume rejects. So, in the case of justice, as in so many other cases, the disagreement between Hume and Reid is, at bottom, a disagreement over their respective conceptions of how the human mind works at its most fundamental level. ${ }^{3}$

\section{Hume and Reid on Motives to Justice}

Reid's argument is offered in opposition to a line of thought that we find in Hume's Treatise, but which, for whatever reasons, Hume does not explicitly repeat in $A n$

2 An exception is Pritchard (2008), which offers a somewhat more detailed discussion of the topic than is usually found. The argument is also mentioned in Wolterstorff (2010) and Harris (2010).

3 In this way, our conclusion here is consonant with, although distinct from, a conclusion reached recently by James Harris. Harris argues that the disagreement between Hume and Reid over justice is rooted in radically different views of the nature of moral judgment, or the moral sense, and the qualities of actions and agents that are recognized through its exercise-a difference, that is, in their respective views of what it is to recognize and respond to the morally salient qualities of actions and agents. While this is probably true, in at least the respects we discuss here, a disagreement in their moral philosophies arises also from disagreements in their respective views of the nature of the mind. See Harris (2010). 
Enquiry Concerning the Principles of Morals. ${ }^{4}$ Hume claims that justice is a natural virtue only if there is some natural motive to do just acts-some motive, that is, that people would have even in the absence of social conventions. He is searching for a motive to do just acts as such, not just a motive to do acts with a certain property that happens to accompany or coincide with the property of being just. Hume runs through a series of possible motives and argues, in each case, that the motive in question is either not natural, or else would not motivate the full range of just acts, some of which provide no benefit at all to anyone. The latter point is intended to show that the motive in question does not favor just acts as such.

Reid may have been the first of the many commentators to note one particularly peculiar aspect of Hume's discussion: his exclusive interest in one branch of justice, namely the justice involved in respecting property rights, to the neglect of other branches. Hume does not claim, for instance, that there is no natural motive to physically harm those who have physically harmed others. Nor does he claim that someone who is confined against his will has not thereby suffered a harm if there are no social conventions. He is really interested in the question of whether there is a natural motive to restore to people those things that are theirs, or a natural motive to respect their decisions not to give their things to those who need them more than themselves. His interest is with justice in interventions that move objects out of one person's possession and into another's. Intuitively, and glossing over important distinctions (such as those involved in lending, and those involved in cases of great need, among others), we take such givings and takings to be just if, in the end, people have possession over all and only the things that are theirs.

But to claim even that justice in this one domain is not natural is easily seen as a subversive conclusion. It appears to run directly contrary to Locke's claim that, as soon as people mix their labor with objects, they acquire rights to the possession and usage of those objects, a claim which underwrites the thought that property rights are more basic and fundamental than the rights of parties to social conventions. Many in both Reid's time and ours see the thought that property rights are conventionindependent as essential to placing limits on the state's power to take and use that which citizens have worked to make better for their own purposes. To take something that belongs to someone is to wrong him. Normative limits of this sort are not thought to be contingent and absent in places with different conventions. The fact that people are typically or conventionally divested of that with which they have mixed their labor hardly makes that divestiture right. Of course, it is possible that such conclusions do not follow from Hume's position; it may be less subversive than it can appear. But subversive or not, the claim that justice is not naturally approved is a conclusion that Hume takes to follow inexorably from the facts about human motivation. If the

4 In An Enquiry Concerning the Principles of Morals, Hume does imply that justice and property would not be instinctually recognized in the absence of human conventions. But this falls short of a statement of the argument Reid targets. 
disposition to respect and enforce property lines were a natural virtue, then there would be a natural motive to behave in that way; since there isn't, it isn't.

This line of thought of Hume's does not strictly require the converse claim that, were there a natural motive to just acts, then justice would be a natural virtue. But Hume probably believes this. After all, for Hume an act is morally good if it is morally approved of from a disinterested point of view. Such approval typically arises through sympathy with either the person whose act it is, or with those people who are affected by the act, or both. So, insofar as those parties have an "agreeable" feeling either in the performance of the act, or thanks to it, the disinterested spectator, animated by sympathy with them, will have an agreeable feeling, too. Just acts, however, frequently provide no agreeable feelings in anyone affected by them. $\mathrm{X}$ drops an item that was in his possession, and for which he has no use; Y, knowing full well that it was in X's possession first, finds it and can use it to his benefit; $Z$, acting justly, takes the object from $\mathrm{Y}$ and returns it to $\mathrm{X}$. $\mathrm{X}$ is not benefitted by this act. $\mathrm{Y}$ is positively worse off. $\mathrm{Z}$ does not benefit either. So who can the disinterested observer of Z's act sympathize with, in order to generate the requisite positive feeling? Given that $\mathrm{Z}$ was motivated to perform the act, it would seem that he must have had some kind of feeling of approval of it. So, the answer is $\mathrm{Z}$. If $\mathrm{Z}$ could have been motivated to perform the just act, then the disinterested observer will share in Z's approval of the act, and he too will approve it. So, if people are motivated to perform just acts in the state of nature, then they could also sympathize with such motives. This would then pave the way for approving of just acts from the disinterested point of view in the state of nature and, given Hume's moral theory, it follows that just acts are morally good in the state of nature.

Hume thinks, therefore, not just that were there no natural motive to justice, justice would be artificial-that is the point that drives his own argument for the artificial nature of justice-but also that were there a natural motive to justice, it would be a natural virtue. Given this, Reid need only show that there is, and Hume must admit there to be, a natural motive to perform acts whose only merit is conformity to the demands of justice in order to show that Hume is committed to thinking that justice is a natural virtue after all.

This point deserves emphasis. Consider Reid's statement of what he will show in the argument that concerns us here:

[A]s soon as men have any rational conception of a favour, and of an injury, they must have the conception of justice, and perceive its obligation distinct from its utility. (EAP V v, 306)

Reid here identifies two things that, for reasons that will presently be explained and explored, he takes to be possessed "as soon as men have any rational conception of a favour, and of an injury." The first is that they recognize some acts to be just; the second is that they perceive themselves to be obligated to do just things. Reid understands the second of these two things in a radically different way from the way in which Hume understands it. Reid takes just acts to possess essentially the quality of being obligatory. He takes that property to be "perceived" through the exercise of a natural 
faculty of the human mind-the "moral sense" or "conscience." 5 And he takes anyone who exercises the moral sense so as to recognize that an act possesses the property of being obligatory to be thereby motivated to perform such an act. By contrast, Hume does not think of the moral sense as a distinct mental organ. While there is a question of exactly how it should be understood for Hume, it is clear that he takes an exercise of the moral sense to amount to the exercise of other, independent faculties of mind in a particular setting. To exercise the moral sense, for instance, might be just to feel sympathy while considering an action or agent in a disinterested way. ${ }^{6}$ Further, and importantly, he does not think of the quality of being obligatory as a property of actions that is somehow "picked up" by exercises of the moral sense but is present in the acts independently. Rather, he seems to think of moral qualities of this kind as present in actions and agents in part in virtue of the fact that people respond in certain ways when they consider them in a disinterested way.

But, and this is the important point, these differences regarding the second of these two things that Reid takes to be present "as soon as men have any rational conception of a favour, and of an injury" matter very little given our purposes here. The reason is that Hume grants too much, even by his own standards, if he concedes the first thing to follow. That is, if Hume allows that we naturally recognize, for instance, that an object that has long been in a person's possession is owed to him, or that he deserves to use it as he sees fit, then he would have to allow that we naturally approve of acts that give people what they are owed or deserve in this sense. And from this it will follow that justice is a natural virtue, not an artificial one: the approval serves as the natural motive, and if there is a natural motive to do just acts, then Hume is committed to thinking that justice is a natural virtue. ${ }^{7}$ So, although Hume and Reid disagree about how we would get from the claim that we naturally conceive of acts as just and unjust to the further claim that justice is a virtue independently of social conventions, they would agree that we can make that inference. The result is that Hume must find a way to block the very first step of Reid's argument. He must not accept that "as soon as men have any rational conception of a favour, and of an injury, they must have the conception of justice."

5 Immediately preceding the passage quoted above, Reid states, "[W]hen men come to the exercise of their moral faculty, they perceive a turpitude in injustice, as they do in other crimes, and consequently an obligation to justice, abstracting from the consideration of its utility" (EIP V v, 306).

6 In fact, Reid recognizes this feature of Hume's view and offers general criticisms of the project of accounting for morality in terms of animal motives. As can be seen from Hume's discussion of actions produced principally by explicitly moral motives (Hume 2007, 3.2.1), Hume would consider it absurd to account for morality in terms solely or principally by reference to such explicitly moral motives. It is essential to his view, that is, that the exercises of the moral sense are not of an entirely different sort from the exercise of other faculties of mind.

7 It is important to note that, when we reference "a motive to do just acts," we mean to discuss a motive to do an act insofar as it is just. Many just acts are also beneficent acts, but the motive of beneficence is not, in those cases, a motive to do just acts. This is important because it underscores why, for Hume, justice would not be a natural virtue unless there were a natural motive to perform just acts whose sole recommendation is their status as just acts. 
In his argument for the claim that even without the help of social conventions people conceive of acts as just and unjust, Reid exploits Hume's concession that gratitude and resentment are natural feelings. Hume is adamant that it is naturally virtuous to feel and act grateful, especially towards one's parents:

Of all crimes that human creatures are capable of committing, the most horrid and unnatural is ingratitude, especially when it is committed against parents, and appears in the more flagrant instances of wounds and death. (Hume, 2007, 3.1.1)

Gratitude is an appropriate response to a favor, thinks Reid. So, Hume must think that we naturally conceive of some acts by others as favors (and injuries, in the case of resentment). It would seem to follow, then, that whatever conceptions one must have in order to conceive of an act as a favor can be had without the help of social conventions. Add the further plausible claim that acts are not favors unless the recipient of the bestowed good is not already owed it and it would seem to follow that gratitude is natural only if the conception of some objects as undeserved is natural. The question of whether Hume can reject Reid's argument at just this point will be discussed in section 4. There we consider the question of whether Hume ought to agree that the facts about our naturally grateful (and resentful) responses show something of importance about our natural conceptions of those acts to which we respond with gratitude and resentment.

But even if Hume agrees that we do indeed naturally conceive of some givings and takings as undeserved, it is a further step to the claim that we therefore conceive of others as deserved. And Reid's argument relies on a general principle about conceiving contradictories to establish this point. But perhaps we can conceive of the absence of desert without conceiving of its presence. Now, to anyone who accepts the plausible view that the concept of being undeserved is constructed out of some concept of negation and some concept of desert, such a view will appear to be absurd. But that plausible view involves some substantive commitments about the nature of moral conception that we should be careful of casually attributing to Hume. The question of whether the conception of the undeserved entails or involves the conception of the deserved, for Hume, is the topic of section 3.

\section{The Range of Moral Conceptions}

As indicated at the end of the previous section, Reid's argument relies on an instance of the general principle that one cannot conceive one member of a pair of contradictories without conceiving the other. Call this the CBS principle (for "conceive both sides"). The argument does not depend on CBS in its full generality, but only on the specific claim that one cannot conceive oneself as undeserving of a particular object unless one can also conceive oneself as deserving. Regardless, Reid does accept CBS. In fact, this principle is deeply entrenched in Reid's philosophy of mind. His independent commitment to it is expressed most clearly in his Essays on the Intellectual Powers 
of Man where he discusses Hume's claim that conceivability entails possibility. In presenting one of his objections to the principle that conceivability entails possibility, Reid attributes CBS to Hume, and provides, as evidence, a direct quote from $A$ Treatise of Human Nature:

Every proposition carries its contradictory in its bosom, and both are conceived at the same time. "It is confessed, says Mr HUME, that in all cases where we dissent from any person, we conceive both sides of the question, but we can believe only one." From this it certainly follows that when we dissent from any person about a necessary proposition, we conceive one that is impossible; yet I know no Philosopher who has made so much use of the maxim, that whatever we conceive is possible, as Mr HUME. A great part of his peculiar tenets is built upon it; and if it is true, they must be true. But he did not perceive, that in the passage now quoted, the truth of which is evident, he contradicts it himself. (EIP 4 iii, 331-2)

The remark that Reid quotes from the Treatise seems at first glance to support the attribution of CBS to Hume. But, this initial appearance is deceptive. The remark appears in the middle of Hume's discussion of belief. Hume is attempting to spell out and defend his view that belief differs from mere conception only in the manner of conceiving (as opposed to differing from conception in kind). To illustrate his position, he offers a discussion of a case of disagreement or dissent, asking how those two states differ from belief. It is worth quoting Hume's passage at length:

Wherein consists the difference betwixt believing and disbelieving any proposition? The answer is easy with regard to propositions, that are prov'd by intuition or demonstration. In that case, the person, who assents, not only conceives the ideas according to the proposition, but is necessarily determined to conceive them in that particular manner, either immediately or by the interposition of other ideas. Whatever is absurd is unintelligible; nor is it possible for the imagination to conceive any thing contrary to a demonstration. But as in reasonings from causation, and concerning matters of fact, this absolute necessity cannot take place, and the imagination is free to conceive both sides of the question, I still ask, Wherein consists the difference betwixt incredulity and belief? since in both cases the conception of the idea is equally possible and requisite.

'Twill not be a satisfactory answer to say, that a person, who does not assent to a proposition you advance; after having conceiv'd the object in the same manner with you; immediately conceives it in a different manner, and has different ideas of it. This answer is unsatisfactory; not because it contains any falsehood, but because it discovers not all the truth. 'Tis confest, that in all cases wherein we dissent from any person; we conceive both sides of the question; but as we can believe only one, it evidently follows, that the belief must make some difference betwixt that conception from which we assent, and that from which we dissent.

(Hume 2007, 1.3.7; emphasis added)

Hume intends the "confession" that Reid notes-which appears to be a statement of CBS - only for a limited range of cases. The context for the quote includes two stories: one for demonstrable/intuitive contents (the category that serves as the fore runner of the first Enquiry's "relations of ideas") and the other for causal/factual judgments ("matters of fact"). Hume can, at most, be taken as endorsing CBS as restricted to matters of fact. 
So, we know that Hume does not think that conceiving of two and two as equaling four requires also conceiving of two and two as not equaling four. We can grant Reid that Hume thinks conceiving that bread nourishes requires also conceiving that bread does not nourish. What about conceiving of some good office $\mathrm{O}$ as being undeserved? Unfortunately, nothing in the Treatise or the Enquiries makes it clear what Hume's stance about such a case would be. In Treatise 3.1.1, titled "Moral Distinctions not Deriv'd from Reason," Hume seems to argue that moral claims are neither demonstrative or intuitive relations of ideas, nor non-demonstrable matters of fact. ${ }^{8}$ This makes it difficult to assess whether the conception of an act as undeserved would be more like the conception of matters of fact-and thus, subject to a version of the CBS principle-or outside the application of CBS, like relations of ideas.

Before moving on, it is worth noting that a principle like CBS has different import for Reid than it does for Hume. Since Reid takes us to be able to conceive impossibilities, for instance, he would take us to be able to conceive of arbitrary acts as falling under arbitrary moral predicates, independent of his views on which actions are morally good or bad and how they come to have that status. As we continue to consider the status of the CBS principle (as it applies to moral claims) for Hume, it will be important to keep in mind that the real concern, for Reid, is whether it is possible to have a conception of some moral status without possessing the conception of the contrary moral status. Thus, even if Hume allows that one can conceive of act A as unjust, without thereby being able to conceive of act A as just, Hume would still be in trouble if his view required that one cannot conceive of act $\mathrm{A}$ as unjust, without thereby conceiving of some other act as just.

What really complicates any attempt to adjudicate whether Hume is forced to accede this point is that the view put forward in Treatise 3.1.2 ("Moral Distinctions Deriv'd from a Moral Sense") outlines Hume's sentimentalist view of moral judgment, but does not discuss (nor even suggest) a view of (mere) moral conception. In fact, nowhere in the Treatise are we given an explicit indication of a positive account of mere moral conception. Even extrapolating a view of moral conception from the explicit view of judgment is made difficult by the wide variety of interpretations of Hume's account of moral judgment (e.g., ideal-agent realist, speaker-subjectivist, emotivist, projectivist, etc.). ${ }^{9}$ Some of these views, although not all, positively entail a theory of the nature of (mere) moral conception. Any straightforwardly "cognitivist" interpretation of Hume's views of ethical judgment - any interpretation, that is, under which moral judgments are to be equated with factual beliefs-will entail an account of moral conception.

8 Some of the scholars mentioned in footnote 9 would contest this characterization of Hume's argument in 3.1.1.

9 Some examples: David Norton interprets Hume as a moral realist, Anthony Flew reads him as an emotivist, and Simon Blackburn labels him a projectivist. Peter Kail reads Hume as a projectivist (though not in the same sense as Blackburn), and Rachel Cohon defends a cognitivist interpretation. This brief, incomplete list is provided merely to illustrate the diversity of interpretations. Reconciling what each of these labels amounts to, and how they relate to one another, is beyond the scope of this essay. For a thorough introduction to Hume's moral philosophy and the interpretive debates surrounding it, see Cohon (2010). 
Whatever the content of the belief that is to be equated with moral judgment is on such interpretations, it would also be available for mere contemplation. For instance, say we attribute to Hume the position that to judge an act to be wrong is to believe that disinterested observers would feel disapprobation on contemplating it. Under such a view, to conceive of good or beneficial act A as being undeserved would then be to conceive of not feeling disapprobation at the disinterested conception of failures to provide A. It would seem to follow that moral conceptions are no different from conceptions of matters of fact and, so, Hume would be committed to the claim that CBS applies to them, just as Reid assumes. ${ }^{10}$

Things are somewhat more complicated if we attribute to Hume some form of noncognitivism according to which to make a moral judgment is, at least in part, to exhibit (or be disposed to exhibit) some kind of emotional reaction that is not, itself, capable of truth or falsity. We can imagine an advocate of such a position denying that there is such a thing as moral conception. Say that a moral judgment is a sentimental response to a descriptive conception of an act, where the sentimental response does not involve any conception at all. On such a view, that is, there is no difference in the conceptions of the person who thinks, "S took something that was in my possession and with which I mixed my labor" and the person who thinks "S did me an injury by taking something that was in my possession and with which I mixed my labor." Both conceive of the act and both attribute a set of non-moral properties to it. They differ in their feelings, not in their conceptions. It is not hard to imagine taking a consequence of such a view to be that there is no such thing as moral conception. There are just conceptions of nonmoral qualities and there are sentimental responses to them. If that is Hume's position, then he would take the very idea of moral conception to be problematic, and so would not accept the CBS principle when applied in the way Reid hopes to apply it.

The CBS principle has been useful for drawing out these complications for a Humean account of moral conception, but it is important to remember that the issue is not whether conceiving of some act $\mathrm{A}$ as unjust requires also possessing the conception of $A$ as just. The issue is whether it is possible to conceive of injuries, for example, as unjust, without having any conception of justice. And the point remains the same: on a view that denies that any moral conception occurs, there is no such thing as conceiving of justice and so no obstacle to conceiving of injuries without conceiving of justice.

However, the advocate of such a non-cognitivist position about moral judgment might not take such a hard line about moral conception. Such a person could say that, trivially, anyone who judges an act to be morally good thereby conceives of moral goodness; perhaps the sentimental response to the conception of the act's descriptive properties involves, or just is, the conception of the act's moral quality. When moral conception is understood in this way, the CBS principle does not hold in the moral domain. There may be well-constituted rational people who cannot conceive

10 Things are further complicated by the murky modal status of facts about the constitution of human psychology in Hume's view, an issue that arises also in connection with Hume's views on the necessary connection in causation, the connection between conceivability and possibility, and other topics. 
of acts of certain morally salient descriptive types without feeling approbation or disapprobation from the disinterested position, in which case, such acts could only be conceived as morally good by such people. ${ }^{11}$ There may even be such people who are only constituted so as to feel approval, and no disapproval. Such people would have conceptions, in the weak sense of that term under consideration here, only of morally good qualities, but not of morally bad ones. ${ }^{12}$ It follows that if Hume accepts a form of non-cognitivism about moral judgment, he would be unmoved by Reid's inference from the claim that we naturally conceive of some objects as undeserved by us to the claim that we conceive of others as deserved. It could be that we are naturally disposed to respond with moral approbation and disapprobation to undeserved givings and takings, respectively, and not to deserved. If there is no more to moral conception than the having of such sentiments, then Reid's argument fails. What follows, however, is not that Reid's argument fails, full stop. It is not clear that the having of a sentiment lacking in descriptive content can amount to a conception of any kind. To know if it could, we would have to know more about what criteria a mental act needs to meet in order to count as a conception. Does any sentiment lacking in descriptive content meet such criteria? It is impossible to say without spelling out the criteria in question. In short, examining the force of Reid's argument against a non-cognitivist about moral judgment, which Hume very well may have been, requires a deeper examination of the sense in which sentiments, particularly moral sentiments, are contentful. Reid's argument is effective only against those who hold that moral sentiments are bearers of content in a way similar enough to matter-of-fact beliefs to warrant the conclusion that, when we conceive one side of the question, we also conceive the other.

One thing that makes it especially difficult to adjudicate the issue, then, is that Reid is not able to provide an example of a specific affection we feel towards acts of justice as such, and he recognizes that, in children, gratitude and resentment are provoked indiscriminately. We will shortly turn our attention to the issues surrounding Reid's developmental account of gratitude and resentment, but it is worth observing that, if Hume adopts a view on which moral conception consists in sentimental reaction, and there is no distinctive sentimental reaction towards just acts (prior to socialization), Hume is in a good position to grant that gratitude and resentment are natural affections, while affirming that justice is an artificial virtue.

\section{Developing Passions: Artifice vs. Maturation}

Reid's argument is motivated in part by observation of the development of moral sentiments in children. He notices that children respond positively, with gratitude, to

11 For discussion of a closely related issue, see Gendler (2000).

12 Arguably, the possibility of such a person would tell against any meta ethical theory that allowed it. Perhaps someone who has positive reactions to benevolent acts without also having negative reactions to malevolent acts is not actually judging benevolent acts to be good. Perhaps to truly value positive effects of acts on human beings one must also disvalue negative ones. 
any "good office" done by another and negatively, with resentment, to any harm done to them. In small children, these responses are insensitive to the facts about others' intentions - children respond positively to good offices even if those good offices are performed with intent to harm, for instance. The responses are also insensitive, in children, to the facts about what they are owed, or what they deserve. The child, for instance, responds with gratitude to the return of an object that had been taken from his possession by another child, even though that object was owed to him. (More, shortly, about the sense of "ownership" involved here.) But, as children grow older, they come to respond differently depending on whether the beneficial or harmful acts were performed with good or bad intent, and depending on whether the benefit or harm was owed, or deserved. Eventually, that is, they respond with gratitude only to good offices that were intended to benefit and when the benefit was not due to them; and they respond with resentment only to bad offices that were intended to harm and when the harm was not owed to or deserved by them. The second change-the alteration of the moral sentiments in response to the facts about what is not owed rather than the facts about intention-is of particular importance to the argument that Reid is offering. It is from this change that Reid derives the claim that when children grow to the age of reason they have a conception of what is undeserved, or not due to them. In other words, it is from the fact that rational adults respond differentially depending on whether the benefit or harm received was owed to them that Reid reaches the conclusion that rational adults have the conception of some things as undeserved by them. As we saw in the previous section, the further claim that rational adults have the conception of things as owed to them, given that they have the conception of some things as unowed, is problematic. But for the purposes of this section it will be granted to Reid. The question under discussion in this section is whether Hume need accept that the facts about the ways our sentiments are modulated once we reach the "age of reason" entails that we conceive of the quality to which we differentially respondnamely, the quality of being undeserved or unowed.

Can, or ought, Hume reject this inference? Perhaps he should claim that the facts about the ways our responses are modulated do not entail facts about our conceptions of objects as unowed? But before considering this possibility, it is important to head off a potential misunderstanding. One might worry that it begs the question against Hume to say that in the state of nature human beings respond differently depending on whether what they receive from another is deserved, or owed. After all, Hume thinks that there is nothing owed or deserved (at least no property owed or deserved) prior to the enactment of human conventions. To insist that people respond differentially to the facts about what is owed in the state of nature is to imply that there are such facts, which is exactly what Hume denies.

However, the reason that this concern is based on a misunderstanding is this. Reid's point about the ways in which our sentiments are modulated once we come to the age of reason can be made without appeal to facts about what is owed per se. The point can be made, instead, through appeal to the kinds of facts that both Reid and 
Hume allow to entail facts about what is owed in the world as it is today, littered as it is with social conventions. That is, the differential response might be to facts about possession and non-value-laden facts (such as what one has mixed one's labor with), rather than facts about what is owed thanks to the facts about possession and other non-value-laden facts. X finds a piece of wood that was never in anyone's possession. He takes possession of it, cuts it and uses it to build a birdhouse which he hangs in a tree near where he lives. The wind blows the birdhouse away and it is found by $\mathrm{Y}$, who returns it to X. Does X feel grateful? Reid thinks that, assuming that $\mathrm{X}$ has reached the age of reason, he does not. He might feel positively towards $\mathrm{Y}$, but it is not gratitude that he feels. (He may feel grateful to $\mathrm{Y}$ for going out of his way. But this feeling is not gratitude for the return of the bird house per se.) He responds differently than a child would. The child would respond with gratitude. But because of the fact that X possessed the wood and built the birdhouse himself, he responds in some other way. Notice, as just described, that the difference in the way in which $\mathrm{X}$ responds to $\mathrm{Y}$, on the one hand, and the way the child would, on the other, is not explained through appeal to facts about what anybody is owed or facts about what belongs to anyone, or any other morally charged notions of this kind, but merely through appeal to the facts about possession and labor-mixing. To avoid begging the question against Hume, Reid must characterize the change in our moral sentiments on reaching the age of reason in these terms. We respond differently in light of facts that, in the actual world, are constitutive of facts about ownership but which may or may not be constitutive of such facts in a world where there are no social conventions.

But say Hume grants to Reid that, even without help from conventions, people respond differently to receipt of benefit or harm, when they reach the age of reason, depending on the facts about possession and labor-mixing. Roughly speaking, and glossing over complexities in the rules of property, an adult responds with gratitude only if the object given to him is not something formerly in his possession with which he mixed his labor, and responds with resentment only if the object taken from him is. If Hume agrees to this, he still might claim that such facts entail nothing about the conceptions of desert of those who respond in this way. Why should Reid think that the only way to explain such differential response is through appeal to conceptions of what is deserved and undeserved on the part of those who respond in these ways? A plant grows differently depending on whether the sun shines down on its left side or its right-it grows towards the sun, wherever the sun happens to shine. But this does not show that the plant has a conception of the sun's location. A bee shows greater interest in novel flowers, of a color it has never seen before, than it does in those of familiar colors. But this does not show that the bee has a conception of novelty. Why should it be any different in our case? Why should the fact that we respond differently depending on the facts about possession and labor-mixing show that we have a conception of those facts, much less that we have a conception of the facts about desert that we now, in our civilized state, take the facts about possession and labormixing to entail? Perhaps we respond differentially thanks to representations of the 
relevant facts, but not through mental representations of the relevant facts. Perhaps the differential responses in our sentiments are like goosebumps: they are modulated by air temperature, and so the air temperature is represented by something it causes, but it is not mentally represented. The fact that goosebumps are modulated by temperature doesn't show that we have a conception of the temperature.

Reid takes the inference from the facts about the modulation of the moral sentiments in rational adults to the claim about our conceptions to be unproblematic. In fact, the inference is unproblematic for someone who accepts a collection of intertwined views about motivation, active power, and moral assessment, almost all of which Hume would deny, and all of which Reid asserts. In particular, he has a view of what it is to act on a rational motive, as opposed to an animal motive, a view about what must be true of a person for an act to be attributed to him, and a closely related view about what is involved in the expression in action of a character trait like the virtue of gratitude. To see the relevance of these views to the point at issue, first note that both Reid and Hume take the person who feels gratitude to be motivated to perform grateful actions; such a person is motivated to express gratitude. So, the question of what a person would feel in response to the receipt of an undeserved benefit by someone intending only good and the question of what a person would be motivated to do in response to such an act are not independent. The feeling may be distinct from the motive itself-Reid would say it is, Hume would say it is notbut regardless, the feeling at least is accompanied by a motive to perform grateful actions in response. So, to note that there is a change in the moral sentiments as the child reaches the age of reason-he now feels gratitude only in response to receipt of undeserved benefits, where previously he responded even to deserved benefits with gratitude-is also to note a change in his motivations. After he comes to the age of reason, the child is motivated to respond gratefully only if the benefit was not deserved.

What kind of motivation is present in such a case? Reid would classify such a motive as a "rational motive." Much earlier in the Essays on the Active Powers he has distinguished the rational "principles of action," or motives, from the mechanical and animal, like so:

Mechanical principles of action produce their effect without any will or intention on our part.... Animal principles of action require intention and will in their proper operation, but not judgment.... [T] he rational principles of action in man ... have that name, because they can have no existence in beings not endowed with reason, and, in all their exertions, require, not only intention and will, but judgment or reason. (EAP III iii.i, 152)

We shortly later learn that Reid takes there to be two very different ways in which a rational motive can involve judgment. First, one can be motivated in part thanks to the fact that one judges a particular act to be a means to some end one has. But, second, and much more importantly, one can acquire an end thanks to the fact that one makes a particular judgment. Reid writes, 
[A]mong the various ends of human action, there are some, of which, without reason, we could not even form a conception; and that, as soon as they are conceived, a regard to them is, by our constitution, not only a principle of action, but a leading and governing principle, to which all our animal principles are subordinate, and to which they ought to be subject.

(EAP III iii.i, 153)

The two ends that Reid has in mind, as he immediately makes clear, are one's good upon the whole and one's moral duty. The claim is that to conceive of one's good upon the whole, or to conceive of one's duty, is thereby to have it as one's end that one achieve one's good upon the whole and to have it as an end that one do one's duty. Conception of these things is enough to generate motivation to pursue them, and not as a means to some other end, but as ends in themselves.

To pursue something as an end is for one's behavior to be explicable, in part, by citing the end, or by citing the fact that one's behavior is (believed by oneself) to bring oneself closer to achieving the end. But, in addition, it is for the explanation through appeal to the end to be final. There is no answer to the question of why one pursues that end, for to answer such a why-question would be to cite some further purpose that is served through such pursuit, and if there were such a further purpose then the end in question would not be, in fact, an end at all. If this is right, then there is a very close relation between one's end in action and the first principles governing one's behavior. To cite a first principle in explanation of a particular phenomenon is to silence further why-questioning. If there were an explanation for the fact that a particular phenomenon is subsumable under a first principle, then the principle in question would not be first.

Reid takes any first principles to be true in virtue of the resolution on the behalf of some agent to act in accordance with it. The fundamental laws of nature are true thanks to the fact that God is resolved to act in accordance with them. They are, as Reid puts it, "fixed resolutions" on God's part. Similarly, the fundamental principles governing human behavior are fixed resolutions either on the parts of human beings, or on the parts of other agents, such as God. Only in the former case, however, is conduct subsumable under a particular first principle genuinely attributable to the creature whose conduct it is. Your conduct is your conduct, in the sense that matters to, among other things, moral evaluation, only because the fundamental rules under which it is subsumable are true thanks to the fact you are resolved to act in accordance with them. This is not true of, for instance, the beating of your heart. The beating of your heart is subsumable under a rule which is, itself, subsumable under some other rule, and so on, until, ultimately, we identify some first principle that the beating instantiates which is not, itself, subsumable under any rule but is true only thanks to the fact that God is resolved to act in accordance with it. But your grateful action, for instance, is attributable to you only thanks to the fact that you are fixedly resolved to act in accordance with the rule specifying grateful actions in response to the conferral of undeserved benefits by another. You have it as an end that you perform actions that 
conform with that rule, and it is thanks to that fact that the grateful act is attributable to you as such. Equivalently, it is only thanks to the fact that you are resolved to act in accordance with such a rule that you are rightly said to possess the character trait, the virtue, of being a grateful person.

Further, Reid holds that to have a fixed resolution to act in accordance with a particular rule, one must have a conception of that rule. And further the conception of the rule requires conception of all of the various properties of objects that are referred to by the rule. So, if it is possible to perform grateful acts without the help of human conventions, it must be possible, thinks Reid, for a person in a world without social conventions to conceive of all of the properties of agents and objects that are invoked in the rules of gratitude, or the rules that grateful people are fixedly committed to following.

So, what, exactly, are the rules of gratitude? It was suggested above that Reid begs the question against Hume if he insists that the difference in the moral sentiments of gratitude and resentment had by children, on the one hand, and had by those who have come to the age of reason, on the other, is explicable only by appeal to the normative notions of desert and ownership. The change must instead be characterized as marking a difference in the way in which people come to modulate their sentiments in response to the facts about possession and labor-mixing; facts that, uncontroversially, constitute ownership and desert in a civilized state in which there are social conventions. If the rules of gratitude similarly invoked only the notions of possession and labor-mixing, and did not say anything about ownership, entitlement, desert, and the like, then it would not follow that the attribution of grateful acts to an agent required conception of these moral properties by the agent.

Here, however, another controversial doctrine of Reid's is playing a role in his thinking. This is the view that an act is not morally valuable unless it is motivated in part by a conception of it as morally valuable. As Reid puts the point:

A being who has no more conception of moral goodness and baseness, of right and wrong, than a blind man hath of colours, can have no regard to it in his conduct, and therefore can neither be virtuous nor vicious. (EAP IV iv, 299)

To have a conception of the facts about possession and labor-mixing, while lacking a conception of ownership and desert would be analogous to having a conception of the facts about the way in which an object reflects light while lacking a conception of the color of the object. Just as we need to have the faculty of sight in order to have the conception of color, we need to have the faculty of conscience, or the moral sense, to have the conception of the moral properties to which the facts about possession and labor-mixing give rise. Growing to the age of reason, for Reid, is important only because the concomitant of the faculty of reason is the moral sense. But the crucial point for our purposes here is that an act performed merely from a conception of a rule requiring positive response when someone gives you something that you never 
possessed or mixed your labor with would not be a virtuous act. In particular, it would not, for Reid, be a grateful act but would, instead, be a pantomime of a grateful act. ${ }^{13}$

So, although the non-question-begging point is only that the rational adult's sentiments are modulated by the facts about possession and labor-mixing, Reid needs the further claim that the acts the rational person performs in response are genuinely grateful and so involve a conception of the facts about ownership and desert that are constituted by the facts about possession and labor-mixing. Only if his conduct is genuinely subsumable under the rules of gratitude, rules which he is fixedly committed to following, can he be attributed with having performed a grateful act.

In short, there is an important and complex line of reasoning behind Reid's inference from the claim that, even in the absence of social conventions, rational adults feel gratitude in response to receipt of a good object only if the object is not one that they possessed and mixed their labor with, to the further claim that rational adults conceive of people as deserving the use and possession of some objects. Reid thinks this follows because he thinks that rational adults in a world without conventions perform genuinely grateful actions that are attributable to them. The attribution of such actions requires that the agents to whom they are attributed are fixedly committed to the rules of gratitude. Fixed commitment to a rule requires a conception of that rule. And the rules in question invoke the quality of being undeserved. And so it follows that to even perform a grateful act one must have a conception of the object received as one to which one was not already entitled.

Hume denies so much of the picture that underlies Reid's thinking on this point that it is not possible to detail all of the disagreements here. Still, consider the claim that one cannot attribute an action to a person in the sense that is relevant for moral responsibility without also taking the laws under which that action is subsumed to be true, thanks to a resolution on the part of the person to act in accordance with them. Not only does Hume deny that laws are ever true in virtue of agents' resolutions to act in accordance with them, but he also denies that, even if this were so, such a resolution would be required for moral responsibility. Hume famously claims that determinism is required for moral responsibility since there must be an exceptionless law linking an agent's behavior with her motive and character-which is what he takes us to hold people accountable for-for us to be justified in holding the agent responsible for the behavior. But he does not think that the law in question must be true by virtue of some resolution on the part of the agent. His compatibilism allows that the law in question might be true only because God is resolved to act in accordance with it, or for any other reason, and, yet, the action would be attributable to the agent in all the ways that matter for responsibility. So, Hume would reject Reid's reasoning here, even if he were

13 Notice that, by contrast, Hume thinks that a large class of acts that are motivated by a conception of them as grateful are not grateful acts. He especially has in mind people who perform grateful acts grudgingly, recognizing that they are grateful acts, but feeling no positive feeling towards them. (See Hume 2007, 3.2.1). 
to demur from invoking his well-known views of the nature of causality and the laws of nature, not to mention his denial of Reid's claim that morally assessable action must be performed from a belief about its moral value.

When it comes to the inference from the facts about the ways in which our sentiments of gratitude and resentment are modulated in the state of nature to the claim that we conceive of some objects as being due to us in the state of nature, Reid's seemingly unencumbered argument is, in fact, relying on an entire model of human agency, laws of nature, and the moral value of acts with which Hume fervently disagrees.

\section{Conclusion}

In building his argument for the naturalness of justice from claims about gratitude, Reid would seem to be arguing ad hominem: he would seem to be starting with premises that Hume, given his admiration for gratitude, would accept. But if Reid's ambition was to argue ad hominem, he falls far short of his aims. It is true that no commentator has claimed that Reid is unencumbered in his effort to respond to Hume's claim that justice is an artificial virtue. Commentators have recognized, that is, that Reid employs premises that Hume would deny. The fundamental dispute between them, expressed by their respective and conflicting positions about the nature of justice, cannot be adjudicated without engaging with their conflicting views on other topics. We take our contribution here to be in expanding the list of disagreements that underlie this one. Determining the degree to which Reid's argument succeeds requires adjudicating disputes about the sense in which moral judgments, insofar as they involve sentiments, thereby also involve moral conceptions or other contentbearing mental states. It requires adjudicating disputes about what needs to be true for an act to be genuinely attributable to a person. And it requires determining what it is for an act to be properly thought of as expressive of a character trait of a person, a question which turns also on the more fundamental question of what a character trait is. Reid and Hume's respective views about justice sit in a web of interconnected views in moral philosophy, but also in the philosophy of mind and action.

\section{References}

Cohon, Rachel. 2010. "Hume's Moral Philosophy." In The Stanford Encyclopedia of Philosophy, Fall 2010, edited by Edward N. Zalta. http://plato.stanford.edu/archives/fall2010/ventries/ hume-moral.

Gendler, Tamar Szabó. 2000. “The Puzzle of Imaginative Resistance.” Journal of Philosophy 97(2): 55-81.

Harris, James A. 2010. "Reid on Hume on Justice." In Reid on Ethics, edited by Sabine Roeser, 204-22. London: Palgrave. 
Hume, David. 2007. A Treatise of Human Nature. Edited by D. F. Norton and M. Norton. Oxford: Oxford University Press.

Pritchard, Michael S. 2008. "Justice and Resentment in Hume, Reid and Smith." Journal of Scottish Philosophy 6(1): 59-70.

Wolterstorff, Nicholas. 2010. "Reid on Justice." In Reid on Ethics, edited by Sabine Roeser, 187-203. London: Palgrave. 